\title{
HUMAN COMFORT AND THE MICROCLIMATIC DRIVERS ACROSS DIFFERENT LAND USE TYPES IN PORT HARCOURT METROPOLIS, NIGERIA *SHAIBU, V.O. and UTANG, P.B. \\ http://dx.doi.org/10.4314/ejesm.v6i6.4S
}

Received 19th June 2013; accepted 14th November 2013

\begin{abstract}
The study identified spatially differentiated thermal human comfort conditions based on heat stress and microclimate data for specific urban built-up land use classes; and examined the influence of certain microclimatic elements on the observed human comfort levels within the coastal milieu of Port Harcourt metropolis. Five days weather (wind speed, air temperature and relative humidity) and human comfort (heat stress) data were obtained for each land use using the Kestrel 4500 weather tracker. In addition, human comfort based on Heat Index (HI) computed using the American Weather Service (AWS) heat index calculator was obtained to determine the associated heat related hazard across the land use types. Data was subjected to descriptive and inferential statistical analysis. Commercial areas had highest mean heat stress (poor human comfort), followed by high density residential areas. A major attribute is the high concentration of population and human activity capable of generating enormous heat. Since relative humidity and air temperature are major determinants of heat stress, the heat Index (HI) obtained using these parameters confirmed that commercial and high density residential areas were more uncomfortable, having higher heat stress and heat index. Port Harcourt may witness continuous increase in heat stress with climate change projections associated with high temperature and relative humidity. Regression Analysis revealed that there is a significant association between microclimate and human comfort, with temperature being a major determinant, followed by relative humidity. Therefore policies that encourage the provision of more vegetation cover should be adopted to curb the effect of urban heat island and heat related diseases on the environment and health of the residents.
\end{abstract}

Key words: Heat stress, human comfort, microclimate, land use, urban, vegetation

\section{Introduction}

Human comfort varies considerably both from city to city and within cities; some areas for example being more effectively ventilated by wind than the others. This variation can be seen to result from a complex interaction between the urban form, urban microclimate and human activity (Steemer and Nikolopoulou, 1996).

Microclimate is the scale at which the influence of the individual surface elements cannot be ignored. This scale has a vertical extension to the top of the canopy layer in particular but also includes the roughness sublayer (Christer, 2006) and at spatial scale between 0.01 and $1,000 \mathrm{~m}$ (Oke, 1978). Microclimate therefore can be defined as the climate at small spatial and temporal scale. The microclimate is the climate of the biological environment (Rosenberg et al., 1983), defined by the meteorological Glossary as the physical state of the atmosphere close to a very small area of the earth's surface, often in relation to living matter. Thus it is climate that influences life, including human comfort and activity directly and at short, medium and long-time scale.

Comfort level, which is the set of physical or psychological circumstances in which somebody feels most at ease and free from physical discomfort or stress, is directly tied to the microclimate. For instance, the human body temperature is supposed to maintain a constant of $37^{\circ} \mathrm{C}$, regardless of the temperature of the air

Department of Geography \& Environmental

Management, University of Port Harcourt, Nigeria.

*Corresponding author: victorysh@yahoo.com 
Human Comfort and the Microclimatic Drivers Across Different ................SHAIBU \& UTANG

around us (Moran, 2006), but for us to be truly comfortable in our environment it is desirable that the temperature of the air around us is maintained at around 10 to $20^{\circ} \mathrm{C}$ depending upon whether we are active or at rest (www.123HelpMe.com, 2011). Thus, when planning and constructing buildings for human habitation, a satisfactory thermal environment is an essential ingredient in building design.

Ahrens (2008) reported that a temperature of $20^{\circ} \mathrm{C}$ on a clear, windless March afternoon in New York City can almost feel balmy after a long, hard winter. Yet, this same temperature may feel uncomfortably cool on a summer afternoon in a stiff breeze. Other microclimatic conditions such as wind force and humidity influence the way heat is exchanged and sensed by the human body. The human body's perception of temperature therefore obviously changes with varying atmospheric condition.

Metje et al., (2008), Zingano (2001) and Theodore et al., (2004) investigated the relationship between physical parameters on human comfort levels and reported that air temperature, wind speed, relative humidity and solar radiation have a clear influence on human comfort level. A combination of these climatic elements is a major determinant of human comfort or apparent temperatures since its coastal/tropical milieu makes temperature equable and generally high throughout the year.

The relationship between temperature and relative humidity combined leads to increase in heat stress, and people could suffer from some heat related diseases, such as heat stroke, muscle cramps, heat exhaustion and fatigue which are dangerous to human health, at certain times of the day and year. Human activities vary in spatial scale, as such the generation of heat energy tends to follow the trajectory and hence microclimate and human comfort. Gulyas et al., (2006) in their study examined outdoor thermal comfort conditions and noted that bioclimatic conditions of sites located close to each other but shaded differently by buildings and plants showed differences in the Physiological Equivalent
Temperature (PET) index amongst these places, which can be as high as $15-20^{\circ} \mathrm{c}$ due to the different irradiation. Secondly, the investigation of different modeled environments (only buildings, buildings+ trees and trees only) showed significant alterations in the human comfort sensation between the situations. The thrust of this study is to examine the spatial variation in comfort levels based on microclimatic and land use variables, and applying a geographic information tool in land use delineation and analysis of variation in comfort levels.

\section{Study Area}

The area under study lies between latitude $4^{\circ}$ $72^{\prime} \mathrm{N}$ and $4^{\circ} 91^{\prime} \mathrm{N}$ and longitude $6^{\circ} 88^{\prime} \mathrm{E}$ and $7^{\circ}$ $12^{\prime}$ E. It cuts across two administrative Local Government Areas, (Port Harcourt city and ObioAkpor) known as Port Harcourt metropolis. These are so closed-knitted and subject to agglomeration and conurbation. It has coastal proximity, which influences the general weather pattern. Mean annual temperature is always high but with a spatial and temporal sequence of slight increase or decrease depending on differential human activities. For most instances, Port Harcourt records a mean annual temperature of $28^{\circ} \mathrm{C}$ (Oyegun and Adeyemo, 1999).

Generally, relative humidity is high with mean annual figure at $85 \%$ (Oyegun and Adeyemo, 1999). The rainy season months of June-October record the highest values. As from April relative humidity increases, peaking in July-September and dropping steadily and continuously till March with the lowest trough in January. With the peak of temperature occurring in March and relative humidity dropping also continuously till March, the human comfort is a function of air temperature at one season and relative humidity during the rainy season.

Port Harcourt metropolis is made up of various land uses and land cover types. The land cover comprises principally un-developed parcels of land and built-up area. The built-up area, which is the focus of the study is characterized by 
such land uses as residential (High, Medium and Low Density), commercial, industrial, and institutional land uses. These suggest that there is also variation in human comfort and the microclimate, since different human activities

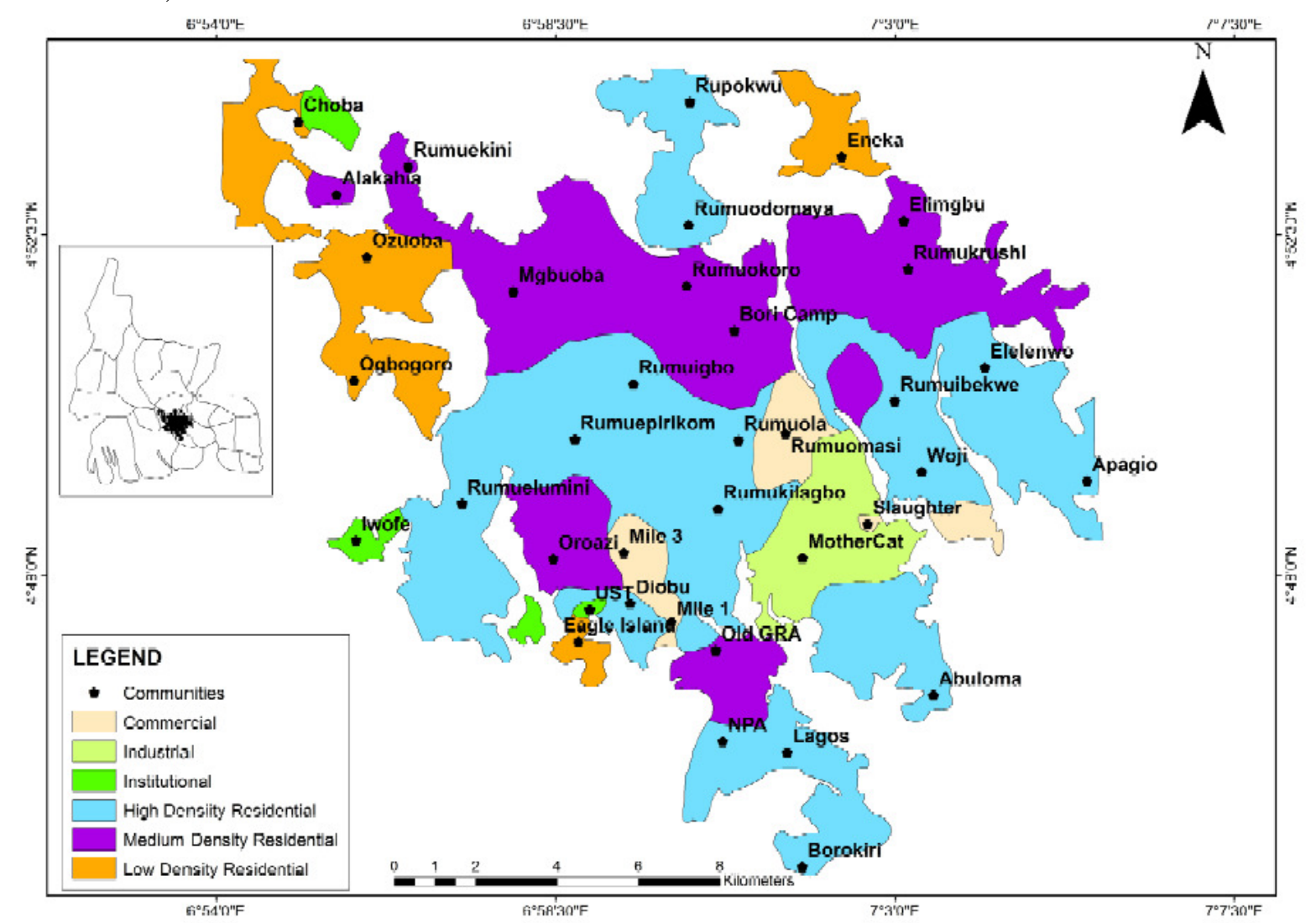

generate different degrees of heat, which, in turn, has effect on the human comfort. The study was conducted in different delineated urban land uses as show in figure 1 .

Figure 1 Land use types in selected built-up areas in Port Harcourt metropolis

\section{Materials and Method}

The microclimatic elements considered for the study are: Air temperature, Wind speed, Relative humidity, and Heat stress. Data on these microclimatic elements was obtained using the Kestrel Weather Tracker Model 4500 instrument. Heat index was also computed as a prelude to constructing the heat index chart for the region under study. This gave a clue on the nature of stress and comfort levels common across land uses given prolonged exposure. Heat index chart was designed in Microsoft excel to demonstrate the human comfort across the various land uses.
The chart combines relative humidity on the horizontal (x-axis) in (\%) and air temperature on the vertical (y-axis) in $\left({ }^{\circ} \mathrm{C}\right)$. This helps to also access the level of heat stress and heat related diseases that are caused by heat stress. This gave an idea of the specific heat related problems per land use. The heat index chart was computed using the National Weather Service Meteorological Conversions and Calculations Heat Index Calculator.

The field survey was carried out for five days during the dry season (March-April) in each of the delineated land use types, including 
commercial, industrial, residential (high, medium and low density), and educational areas. Housing concentration, Social status and Building quality, Population Density was used to classify the residential land use into high, medium and low. The data was collected at different time interval (006 hrs, 1200hrs and 1800hrs). Composite sampling method was thus adopted by taking the readings in different days at the same points.

Analysis of Variance (ANOVA) was used to determine the level of significance of the variation in microclimate and human comfort among the different land use types. Multiple regression analysis was used in explaining the relationship between mean microclimate conditions and human comfort as well as estimation of heat stress from the microclimate in the different land use types. The regression model is of the form:

$$
Y=a+b_{1} X_{1}+b_{2} X_{2}+b_{3} X_{3} \ldots . .+b_{n} X_{n}+e
$$

Where $\mathrm{Y}=$ dependent variable (mean heat stress); $\mathrm{a}=\mathrm{Y}$ intercept; $\mathrm{b}_{1}, \mathrm{~b}_{2}, \mathrm{~b}_{3} \ldots . \mathrm{b}_{\mathrm{n}}=$ the regression coefficients; $X_{1}, X_{2}, X_{3} \ldots . . X_{n}=$ the independent variables; $X_{1}=$ Air Temperature, $X_{2}$ $=$ Wind Speed, $\mathrm{X}_{3}=$ Relative Humidity (mean microclimatic elements); and $\mathrm{e}=$ the residual or random error term.

\section{Results and Discussion}

Table 1 Microclimate across different urban land use types in Port Harcourt metropolis

\begin{tabular}{llllll}
\hline Land use type & \multicolumn{3}{c}{ Mean values of Microclimate elements } & & \\
& $\begin{array}{l}\text { Wind speed } \\
(\mathrm{m} / \mathrm{s})\end{array}$ & $\begin{array}{l}\text { Air temperature } \\
\left({ }^{0} \mathrm{C}\right)\end{array}$ & $\begin{array}{l}\text { Relative Humidity } \\
(\%)\end{array}$ & $\begin{array}{l}\text { Heat } \\
\left({ }^{0} \mathrm{C}\right)\end{array}$ \\
\hline High density & $0.48(0.205)$ & $30.7(0.432)$ & $73.4(1.420)$ & $38.4(1.549)$ \\
Medium density & $0.54(0.194)$ & $30.9(0.713)$ & $75.0(2.407)$ & $39.7(1.792)$ \\
Low density & $0.57(0.178)$ & $29.7(1.410)$ & $76.7(3.347)$ & $36.5(2.605)$ \\
Commercial & $0.46(0.150)$ & $31.5(0.960)$ & $72.2(1.167)$ & $40.2(2.471)$ \\
Industrial & $0.51(0.204)$ & $30.9(0.539)$ & $72.7(1.545)$ & $39.4(1.310)$ \\
Institutional & $0.56(0.216)$ & $29.5(1.195)$ & $76.7(2.948)$ & $35.5(1.971)$ \\
\hline Standard deviation in parenthesis)
\end{tabular}

From table 1 the lowest mean wind speed of 0.46 and standard deviation 0.150 during the survey period was in the commercial land use. The low standard deviation indicates a high level of consistency and reliability of wind. Generally the mean wind speed and standard deviation are low. However, the standard deviations generally show more homogeneity and uniformity of wind speed in the commercial land use within the five days of field survey.

The air temperature in the institutional and low density residential land uses is on the average lower than in the other land use types. On the other hand, these (low density residential land use and institutional) land uses had the highest value of standard deviation. This indicates more homogeneity of air temperature in other land use types within the five days. Thus the low mean daily air temperature and the standard deviation in low density residential and institutional land uses suggest high reliability/predictability of temperature, hence better apparent temperature for these land uses, all things being equal.

Commercial land use had the lowest mean relative humidity and value of standard deviation (1.167) compared to the other land uses. This land use has the highest mean temperature, which is a major determinant of heat stress and discomfort, particularly if combined with low wind seed and high relative humidity. The relative homogeneity in relative humidity tends to correlate with wind speed and air temperature in the commercial land use. This appears to synchronize with the situation in the industrial 
and institutional land uses within these five days of investigation. The low relative humidity helps to reduce or moderate the human comfort. A high relative humidity combined with high values of air temperature and low values of wind speed would have made the commercial land use more uncomfortable.

Heat stress is an increase in human body temperature and metabolism caused by physical exertion and / or a heated environment, which can lead to exhaustion, mental confusion, disorientation, dehydration, loss of consciousness, heart attack, stroke and other fatal illnesses. Heat stress across the land uses indicates the lowest in the low density residential land use but with highest standard deviation. There was more homogeneity of heat stress in the industrial land use than the other land uses. The commercial, industrial, high and medium density residential land uses show higher heat stress. This is in conformity with the result for air temperature, with relative humidity having a moderating effect. A combination of these elements is very important in determining heat stress. According to Park et al (2005), it is commonly accepted that occurrence of heat stress related disease depends on the temperature, humidity, physical work and acclimatization.

\section{Human comfort across urban land use types}

The combination of air temperature and relative accounts for heat stress and this has been expressed in the heat index or apparent temperature concept, developed by R. G. Steadman in 1979 (Moran, 2006; Ahrens, 2008). Heat Index is an accurate measure of how hot it really feels when the effects of humidity are added to high temperature. The Heat Index or apparent temperature, which attempts to gauge the combined influence of temperature and humidity on human wellbeing, accounts for the human body's inability to dissipate heat to the environment as the relative humidity rises (Moran, 2006). The index and associated hazards they pose is as shown in table 2 .

Table 2 Hazards posed by Heat Stress by range of Apparent Temperature

\begin{tabular}{lll}
\hline Category & Apparent temperature & Heat syndrome \\
\hline $\begin{array}{l}\text { Extreme Danger } \\
\text { Danger }\end{array}$ & $\begin{array}{l}130{ }^{0} \mathrm{~F}\left(54{ }^{\circ} \mathrm{C}\right) \text { or above } \\
105 \text { to } 130{ }^{0} \mathrm{~F}\left(41 \text { to } 54{ }^{\circ} \mathrm{C}\right)\end{array}$ & $\begin{array}{l}\text { Extreme danger; heat stroke imminent } \\
\text { Danger; heat cramps or heat exhaustion likely. Heat stroke } \\
\text { possible with prolonged exposure and physical activity }\end{array}$ \\
Extreme Caution & 90 to $105{ }^{\circ} \mathrm{F}\left(32\right.$ to $\left.41{ }^{\circ} \mathrm{C}\right)$ & $\begin{array}{l}\text { Heat cramps or heat exhaustion possible with prolonged } \\
\text { exposure and physical activity }\end{array}$ \\
Caution & 80 to $90{ }^{\circ} \mathrm{F}\left(27\right.$ to $\left.32{ }^{\circ} \mathrm{C}\right)$ & $\begin{array}{l}\text { Fatigue possible with prolonged exposure and physical } \\
\text { activity }\end{array}$ \\
\hline
\end{tabular}

Source: Adapted from Moran (2006)

This index was computed for the five days of field survey in order to describe the peculiar levels of human comfort across the various land uses and the hazards posed by apparent temperature as shown in table 3. It is clear from table 3 that there was need for extreme caution to be taken during the period of the survey in all the land use types looking at the hazards associated with different heat index conditions. Although the average condition altogether was associated with extreme caution but three (3) days during that period, the commercial land use types were observed to be associated with danger. On the whole, given the conditions as prevailing, caution must be taken in the metropolis to avert heat related disaster. Urban design and planning, which encourages urban vegetation (urban forestry), would help to assuage the problem.

Although the land uses are generally uncomfortable, this may not necessarily be uniform across the different land use types. This can be seen from the situation in the commercial area, which shows variation with other land uses. The level of significance of the observed variation is explored next. 
Table 3 Heat Index or Apparent Temperature $\left({ }^{0} \mathrm{C}\right)$ and associated category of action under prolonged

\begin{tabular}{|c|c|c|c|c|c|c|}
\hline Days & $\begin{array}{l}\text { High } \\
\text { Density }\end{array}$ & $\begin{array}{l}\text { Medium } \\
\text { Density }\end{array}$ & $\begin{array}{l}\text { Low } \\
\text { Density }\end{array}$ & Commercial & Industrial & Institutional \\
\hline 1 & $\begin{array}{l}38(\text { extreme } \\
\text { caution) }\end{array}$ & $\begin{array}{l}\text { 36(extreme } \\
\text { caution) }\end{array}$ & 42(danger) & $\begin{array}{l}35 \text { (extreme } \\
\text { caution) }\end{array}$ & $\begin{array}{l}39 \text { (extreme } \\
\text { caution) }\end{array}$ & $\begin{array}{l}\text { 39(extreme } \\
\text { caution) }\end{array}$ \\
\hline 2 & $\begin{array}{l}37 \text { (extreme } \\
\text { caution) }\end{array}$ & $\begin{array}{l}38(\text { extreme } \\
\text { caution) }\end{array}$ & 31(caution) & $\begin{array}{l}39 \text { (extreme } \\
\text { caution) }\end{array}$ & $\begin{array}{l}\text { 38(extreme } \\
\text { caution) }\end{array}$ & $\begin{array}{l}34(\text { extreme } \\
\text { caution) }\end{array}$ \\
\hline 3 & $\begin{array}{l}38(\text { extreme } \\
\text { caution) }\end{array}$ & $\begin{array}{l}40 \text { (extreme } \\
\text { caution) }\end{array}$ & $\begin{array}{l}35 \text { (extreme } \\
\text { caution) }\end{array}$ & 42(danger) & $\begin{array}{l}40 \text { (extreme } \\
\text { caution) }\end{array}$ & 32(caution) \\
\hline 4 & $\begin{array}{l}38 \text { (extreme } \\
\text { caution) }\end{array}$ & 41(danger) & $\begin{array}{l}34 \text { (extreme } \\
\text { caution) }\end{array}$ & 41(danger) & $\begin{array}{l}37 \text { (extreme } \\
\text { caution) }\end{array}$ & $\begin{array}{l}34 \text { (extreme } \\
\text { caution) }\end{array}$ \\
\hline 5 & $\begin{array}{l}40 \text { (extreme } \\
\text { caution) }\end{array}$ & 41(danger) & $\begin{array}{l}39 \text { (extreme } \\
\text { caution) }\end{array}$ & 42(danger) & $\begin{array}{l}37 \text { (extreme } \\
\text { caution) }\end{array}$ & $\begin{array}{l}38 \text { (extreme } \\
\text { caution) }\end{array}$ \\
\hline MEAN & $\begin{array}{l}\begin{array}{l}38 \text { (extreme } \\
\text { caution) }\end{array} \\
\end{array}$ & $\begin{array}{l}39 \text { (extreme } \\
\text { caution) }\end{array}$ & $\begin{array}{l}36 \text { (extreme } \\
\text { caution) }\end{array}$ & $\begin{array}{l}40 \text { (extreme } \\
\text { caution) }\end{array}$ & $\begin{array}{l}38(\text { extreme } \\
\text { caution) }\end{array}$ & $\begin{array}{l}35 \text { (extreme } \\
\text { caution) }\end{array}$ \\
\hline
\end{tabular}

Levels of Significance of variation in microclimate and human comfort across land use types

Table 4 Analysis of Variance for weather parameters

\begin{tabular}{|c|c|c|c|c|c|c|c|c|c|c|c|c|c|c|}
\hline \multirow{2}{*}{$\begin{array}{l}\text { Source of } \\
\text { variation }\end{array}$} & \multicolumn{4}{|c|}{ Sum of squares } & \multirow[t]{2}{*}{$\mathrm{D} / \mathrm{F}$} & \multicolumn{4}{|c|}{ Variance estimate } & \multicolumn{4}{|c|}{ Calculated F } & \multirow{2}{*}{$\begin{array}{l}\text { Table } \\
\text { value }\end{array}$} \\
\hline & HS & WS & $\mathrm{T}$ & RH & & $\mathrm{HS}$ & WS & $\mathrm{T}$ & RH & HS & WS & $\mathrm{T}$ & RH & \\
\hline $\begin{array}{l}\text { Between } \\
\text { sum }\end{array}$ & 90.3 & 0.05 & 15.4 & 99.2 & 5 & 18.06 & 0.01 & 3.07 & 19.9 & 14.3 & 5.6 & 3.04 & 3.02 & 2.62 \\
\hline Within sum & -32.2 & 1.34 & -24.3 & 157.8 & 24 & 1.26 & 0.06 & -1.0 & 6.6 & & & & & \\
\hline Total sum & 60.1 & 1.39 & -8.9 & 257 & 29 & 2.07 & 0.05 & -.31 & 8.9 & & & & & \\
\hline
\end{tabular}

$\mathrm{HS}=$ Heat Stress; $\mathrm{WS}=$ Wind Speed; $\mathrm{T}=$ Temperature; $\mathrm{RH}=$ Relative Humidity

From table 4, it is clear that heat stress and other associated microclimatic elements varied significantly across the delineated (different) urban land use types given the higher calculated $\mathrm{F}$ over the significance value. The implication is that energy needed to reduce warmth in buildings and even business premises would vary across land uses, although the general demand for energy is high for all the land uses.

\section{Relationship between microclimate and human} comfort across the different land use types

It is established that heat stress is associated with microclimate conditions. For instance the combination of temperature and relative humidity determines the extent of heat, while wind speed exerts a moderating effect. As noted by Ahrens (2008) and Moran (2006), heat stress, which explains the human body's perception of temperature, obviously changes with varying atmospheric conditions. To Ahrens (2008), for instance, a relationship exist between temperature and wind speed to the extent that a similar temperature condition feels differently in different wind condition, being uncomfortably cool on a stiff breeze in a particular season than a windless day in a particular season. Moran (2006) sees the relationship between air temperature and relative humidity as determining apparent temperature. Apparent temperature, also referred to as heat index, is what the air feels like to the average person for various combinations of air temperature and relative humidity. High air temperature in a high humid day is more uncomfortable than same high air temperature in a dry air. Thus air temperature and relative humidity are critical determinants of heat stress. 
The above justifies establishing relationship between wind speed, air temperature and relative humidity on one side and heat stress on the other hand. The results of the analysis of the relationships between these variables generated for each land use type are presented in table 5 and equations $1-6$.

Table 5 Summary of multiple regressions output for different land use types

\begin{tabular}{lllllll}
\hline Land use type & $\begin{array}{l}\text { Regression } \\
\text { coefficient }(\mathrm{R})\end{array}$ & Multiple $\left(\mathrm{R}^{2}\right)$ & $\begin{array}{l}\text { Adjusted } \\
\mathrm{R}^{2}\end{array}$ & $\begin{array}{l}\text { Std error of } \\
\text { estimate }\end{array}$ & F statistics & $\mathrm{F}$ sig \\
\hline High density residential & 0.983 & 0.966 & 0.863 & 0.63264 & 9.434 & 0.234 \\
Medium density & 0.997 & 0.993 & 0.973 & 0.33675 & 48.204 & 0.105 \\
Low density & 0.998 & 0.996 & 0.977 & 0.12511 & 710.721 & 0.028 \\
Commercial & 0.999 & 0.998 & 0.981 & 0.09697 & 1085.385 & 0.022 \\
Industrial & 0.949 & 0.901 & 0.603 & 0.91614 & 0.901 & 0.304 \\
Institutional & 0.963 & 0.928 & 0.711 & 1.18498 & 4.275 & 0.338 \\
\hline
\end{tabular}

It is clear from table 5 that the combination of the microclimatic elements significantly influenced the human comfort levels as represented by the recorded heat stress. The combined influence of microclimatic factors accounted for between 60 per cent and 98.1 per cent of the apparent temperatures, given the adjusted $\mathrm{R}^{2}$. It thus show that the combined influence of these microclimatic factors is not uniform across the different land use types. However, the combined influence was more in the commercial, low and medium density and this confirmed by the low standard error of Estimate. It is pertinent to identify the specific role of each microclimate elements. The specific influence of each element for the different land use types are explained by linear modeling (see equations 1-6).

Regression models:

(a). For high density residential land use $\mathrm{HS}=-76.115-0.150 \mathrm{~T}+0.931 \mathrm{WS}+$

$0.180 \mathrm{RH}$ (1)

t $\quad(-1.580)(-0.524)(3.391)(0.670)$ t sig (0.359) (0.683) (0.183) (0.624)

(b). Medium density residential land use $\mathrm{HS}=-67.286+0.215 \mathrm{~T}+1.092 \mathrm{WS}+$

$0.350 \mathrm{RH}$.

t $\quad(-4.109)(1.905)(7.859)(2.657)$

$\mathrm{t}$ sig (0.152) (0.308) (0.081) (0.229)

(c). Low density residential land use $\mathrm{HS}=-35.068+0.002 \mathrm{~T}+1.004 \mathrm{WS}+$ $0.296 \mathrm{RH}$. t $\quad(-9.822)(0.033)(16.882)(12.976)$

$\mathrm{t} \operatorname{sig}(0.065)(0.979)(0.038)(0.050)$

(d). Commercial land use

$\mathrm{HS}=-84.463-0.115 \mathrm{~T}+1.202 \mathrm{WS}+$

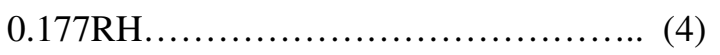

t $\quad(-11.119)(-5.505)(35.188)(5.289)$

$\mathrm{t} \operatorname{sig}(0.057)(0.114)(0.018)(0.119)$

(e). Industrial land use

$\mathrm{HS}=19.043-0.178 \mathrm{~T}+0.663 \mathrm{WS}-$

$1.057 \mathrm{RH} . \ldots \ldots \ldots \ldots \ldots \ldots \ldots \ldots \ldots \ldots \ldots . \ldots . \ldots \ldots$ (5)

t $\quad(0.384)(-0.467)(1.746)(-1.057)$

$\mathrm{t} \operatorname{sig}(0.766)(0.722)(0.331)(0.482)$

(f). Institutional land use

$\mathrm{HS}=-32.481-0.088 \mathrm{~T}+1.158 \mathrm{WS}+$

$0.263 R H . \ldots \ldots \ldots \ldots \ldots \ldots \ldots \ldots \ldots \ldots . \ldots \ldots$ (6)

t $\quad(-0.692)(-0.325)(2.334)(0.530)$

$\mathrm{t} \operatorname{sig}(0.614)(0.800)(0.258)(0.690)$

It is clear from the regression models although that a significant relationship exists between a combination of the microclimatic elements and human comfort, not all the elements had significant influence on heat stress in each land use. The physical characteristics and human activities of each land use as at the time of the survey could alter the way each element influences one another and the human comfort. For instance urban form in terms of concentration of building could attenuate ventilation capability of the area, while intense human activities (industrial and commercial) could create additional heat. It is evident (apart from the medium and low density 
residential area), that wind speed was a major factor in alleviating heat stress, while air temperature and relative humidity accentuated the problem. With the region being predominantly under the influence of calm to gentle prevailing wind, high air temperature and relative humidity, because of its tropical coastal location, high apparent temperatures would continue to be a problem to contain with by the city dwellers. As noted by Utang and Wilcox (2009), the city would continue to experience increased air temperature, requiring increased demand for energy for cooling.

\section{Conclusion}

The increase in rate of heat stress and high heat index has its attending effect on both the environment and the health of residents thereby causing heat related diseases such as Fatigue, Sunstroke, Muscle cramps, Heat stroke and Heat exhaustion. The general air temperature and heat index/stress confirms that Port Harcourt is rather uncomfortable at certain times of the year. The study therefore recommends that adequate space management and planning is a sure way for averting heat related disasters in the city. Techniques and criteria such as energyconservation and planting of shade trees should be developed for city management so that maximum energy conservation values and human thermal comfort of such planting are maintained over time.
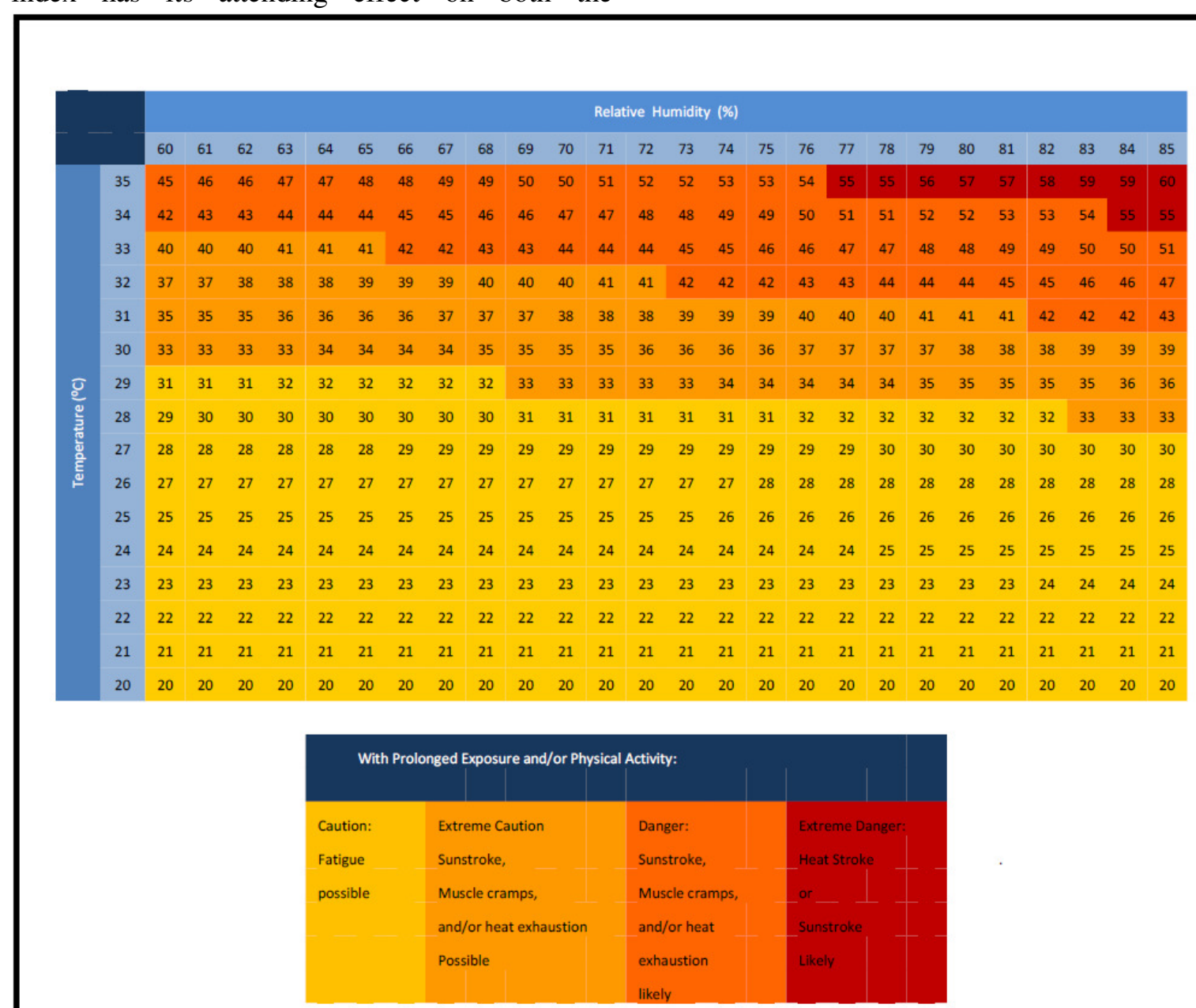

Heat Index Chart of Port Harcourt Metropolis Source 


\section{References}

Ahrens, C. D. (2008), Essentials of Meteorology: An invitation to the atmosphere. United States, Thomson

Christer, J. (2006), Urban Microclimate and Surface Hydro-meteorological processes. KTH Architecture and the Built Environment

Gulyas, A, Janos, U. and Andreas, M. (2006), Assessment of the microclimatic and human comfort condition in a complex urban environment: Modeling and measurements. Building and Environment, 41(21), 1713 - 1722. HelpMe.com (2011), "Investigating the Basic Factors that Affect Human Comfort" 123HelpMe.com. Accessed from http://www.123HelpMe.com/view.asp?id=14777 8.02 Apr 2011

Metje, N., Sterling, M. and Baker, C.J. (2008), Pedestrian comfort using clothing values and body temperatures. Journal of wind engineering and industrial aerodynamics 96(4), 412-435. ISSN: 0167-6105.

Moran, J.M. (2006), Weather studies: Introduction to atmospheric science; Boston, American Meteorological Society

Oke, T.R. (1978), Boundary Layer Climates. Published by Methuens and Co. Ltd., London UK.

Oyegun, C.U. and Adeyemo, A. (1999), Port Harcourt Region. Department of Geography and Environmental Management. University of Port Harcourt, pp 33-66.

Park, D.G., Shin, S.C., Kang, S.W. and Kim, Y.T. (2005), Development of Flexible Self
Adhesive Patch for Professional Heat Stress Monitoring Service. Proceedings of the 2005 IEEE, Engineering in Medicine and Biology 27th Annual Conference, Shangai, China, September 1-4. 4P.

Rosenberg, N.J., Blaine, L.B., and Shashi, B.V. (1983), Microclimate: The Biological Environment, N/Y, Wiley-Interscience Publication

Steadman, R.G. (1979), Effect of Wind, Extra Radiation and Barometric Pressure on Apparent Temperature: Journal of Applied Meteorology, Part 11.

Steemer, K. and Nikolopoulou, M. (1996), Assessing the urban microclimate: Introducing innovative modeling techniques: The Martin Centre for Architectural and Urban Studies, University of Cambridge, Department of Architecture.

Theodore, S., Hanqing, W. and John, Z. (2004), Outdoor human comfort in an urban climate. Building and Environment, 39(3), 297- 305.

Utang, P.B. and Wilcox, R.I. (2009), Applying the Degree Days Concept in indicating Energy Demand due to climate change in Port Harcourt, Nigeria. Port Harcourt Journal of Social Science, 1(2), 89-102.

Zingano, B. W. (2001), A discussion on thermal comfort with reference to bath water temperature to deduce a midpoint of the thermal comfort temperature zone. Renewable Energy, 2(3), 41-7. 